\title{
Cases For Asset Allocation
}

Ducksang Choi, (E-mail: choid@mscd.edu), Metropolitan State College of Denver

\begin{abstract}
Diversification is one of the most important parts of the successful portfolio investment. Within a diversified portfolio an investor should have wide array of assets diversified across multiple classes, including but not limited to stocks, bonds, commodities, currencies, real estates, and limited partnerships. There are also numbers of different investment strategies to consider when approaching the management of these assets. Among these management approaches are the techniques of using separately managed accounts, individual securities or brokerage accounts and mutual funds, or a combination of any or all of these. In addition to these management approaches, there are forces in the financial and global economic universes that need to be appropriately addressed to have effective management of these assets. It is also important for investors to have the appropriate diversifications as well as asset allocations across multiple asset classes within any portfolios. "Asset allocation policy explains, on average, 93.6 percent of total variation in quarterly returns; in particular plans, it explains no less than 75.5 and up to 98.6 percent of total return variation" (Jahnke, William W. 1997). The allocation and selection of these assets needs to be weighted and selected carefully.
\end{abstract}

\section{CASES FOR STOCKS}

tocks, or equities, can be broken down using extensive lists of criteria including sectors, market capitalizations, investment objectives and global locations. Selecting appropriate sectors in the predicted states of the markets is more of an art than a science. Inappropriate selections of sectors could have detrimental impacts on the values of portfolios and the financial well-being of the given entities. At the same time, the reverse is also applicable, in that appropriate selections of sectors could be very beneficial to the values of portfolios.

Size of the companies is a significant factor in the process. Companies publicly traded are placed in one of the four categories of market capitalizations. The four most common categories are large cap, mid cap, small cap and micro cap. Selecting right sizes and blending firms with different sizes could be daunting and cumbersome tasks, but a necessary one nonetheless.

Investment goal of an investor is one of the most important factors to consider when selecting the appropriate equities. One of the most commonly considered investment goals is the opportunity of capital appreciations and the preservation of capitals. These are commonly referred to as growth stocks and value stocks. Finding appropriate balances between growth and value stocks is one of the several things that should be addressed in order to build portfolios that best meet the financial needs of the investors.

Foreign stocks can also play an important role in the performance of the portfolios. Using foreign stocks in portfolios diversifications is a technique that has been in much favor over recent years. American Depository Receipts are the most commonly used instruments when investing in foreign stocks. They are foreign stocks that trade on stock exchanges in the U.S. This results in an ease of trading and makes them the most popular of the foreign equity investments. Another type of foreign equity investment is foreign stocks that are traded on foreign exchanges. They are more difficult to trade for many investors since access to foreign exchanges can be somewhat limited. Emerging markets have been notorious for providing potential for large capital gains, but are also prone to times of extreme volatilities. Careful selection of stocks in emerging markets is essential when managing this type of investment. 
Careful analysis of investments within portfolios is a necessary process that needs to be performed rigorously and thoroughly. There are three primary methods used when analyzing equity securities. They are the dividend valuation model, fundamental analysis, and technical analysis. They are used as stand alone techniques or in any combinations. The dividend valuation model is used to find intrinsic values of the companies using forecasted future dividend payments. There are two different models that can be used in this approach. First is the constant growth model and it is used when dividends paid by a company are expected to grow at a constant annual rate for the foreseeable future. Second is the non-constant growth model and it is used when the dividends paid by a company are not expected to grow at a constant rate for the expected investment timeframe. One problem with the dividend valuation model is that it involves a significant amount of forecasting, which is a difficult task at best. Another problem with this approach is that it is not applicable for stocks that do not pay dividends, which can eliminate this model in valuing many stocks in many sectors and capitalization ranges. The stocks that do not pay dividends, however, are evaluated by an alternative approach known as the price-earnings approach.

Fundamental analysis is the process of analyzing financial information released by companies in order to value the companies and determine whether investments in the companies are appropriate given investment goals. There are two primary processes that are used when implementing fundamental analysis. First approach is the topdown analysis and it examines the upper management of the company to determine their abilities to manage and lead their employees. The process then follows as far down the chain of management as needed to satisfy or verify the concerns of the potential investors. Second approach is doing researches on the financial statements of the companies. It is primarily used to determine the financial health of the firms and identify potential patterns in the operating procedures. This is done by evaluating the statement of cash flows, as well as the balance sheets and the income statements.

Technical analysis is the technique of using charts of previous price history to predict future movements in stocks prices. It is considered to be a futile approach, maintaining that historical performance is no indication of future results, but there is enough trading activities based on technical analysis.

\section{CASES FOR BONDS}

Bonds provide stability, safety of principal and income and they also reduce the overall volatilities of portfolios. There are also a number of different types of bonds that offer different investment opportunities. They are U.S. treasury obligations, U.S. agency bonds, corporate bonds, municipal bonds, and structured notes.

Treasuries are composed of three different types; T-bills, T-notes and T-bonds. T-bills are the shortest term and are typically used for cash management. T-notes are intermediate term and typically used as the benchmarks. Tbonds are the longest term obligations and typically used by large institutional investors such as pension funds, insurance companies, and mutual funds. Treasury obligations also compose the yield curve, which is the graph of the yields on treasury securities against different maturities. As of late the shape of the yield curve has been a common topic of conversations. There are three primary shapes of the yield curve. They are normal, flat and inverted. A normal yield curve is where the yields on the longer term bonds have higher yields than shorter term bonds. A flat curve is where yields are relatively equal across all maturities. And an inverted curve is where shorter term bonds have higher yields than longer term bonds. The yield curve is typically a fairly reliable indication of the overall condition and direction of the economy. Typically a normal shaped yield curve is an indication of a healthy economy. A flattening of the yield curve commonly indicates the beginning of a contraction and an inverted curve commonly signals a recession in the economy.

Debt securities issued by U.S. government agencies play important roles in the fixed income portion of the portfolios. These agencies include the Federal National Mortgage Association (FNMA or Fannie Mae), the Federal Home Loan Mortgage Corporation (FHLMC or Freddie Mac), Government National Mortgage Association (GNMA or Ginnie Mae) and the Student Loan Mortgage Association (SLMA or Sallie Mae). These types of bonds become ideal tools in managing the risks. 
Collateralized Mortgage Obligations (CMO's) may become an effective tool in managing interest rate risks. The convexity that is added to fixed income portfolios can effectively hedge fixed income portfolios against falling interest rates and reinvestment risks, and at the same time, using different types of CMO's can help hedge risks of portfolios with interest rates uncertainty. Interest Only (IO's) CMO's are structured for the holders of the obligations to receive the interest portion of the mortgage payments. These work opposite of typical bonds; as interest rates rise, their prices go up. Principal Only (PO's) CMO's are structured for the holders of the obligations to receive only principal portions of the mortgage payments. They react to the changes in interest rates the same way as normal bonds do; as interest rates rise, prices fall. A pass-through is structured for the holders to receive a portion of interest and a portion of principal from the mortgage payments. All of these structures play important roles in the fixed income portfolios and can provide types of hedges against different environments with changing interest rates.

The corporate bonds portion of fixed income portfolios also play unique roles in this process. The sector selection of corporate bonds can be very similar to that of the sector selection of stocks. One of the other elements in corporate bonds selection is the credit selection. One of the important factors to consider in credit selection is the risk tolerance level of the investors. Corporate bonds offer the holders with opportunities to receive higher returns when they are compared to the returns on treasury or agency obligations, but they have inherently higher levels of risks in general.

Municipal bonds can be particularly advantageous to many investors for several different reasons. First, the interest payments from municipal bonds are exempted from state (in most cases) and federal taxes. For investors in higher tax brackets the municipal bonds can make after tax returns significantly higher than taxable bonds such as corporate bonds or government bonds. It is also advantageous to many investors that municipal bonds are not as highly correlated to treasury obligations as agency or corporate bonds. Municipal bonds also provide good aspects of diversifications. There are general obligation bonds available and they are generally supported by the full taxing authority of the issuing municipality. There are also revenue bonds available and they are supported by revenue generated by the project being funded. Municipal bonds are also commonly considered to be one of the safest investments available. According to Moody's, there has not been any single default in general obligation bond issues in last twenty years.

One of the newest investments available, and possibly one of the most interesting is the emergence of the structured notes. They are debt obligations issued by large investment banks and typically used by many institutional investors. The structured notes are broken down into two parts; synthetic zero-coupon bond, and option. The option portion of the investments provides investors with opportunities to gain exposures to other asset classes that are typically not available to many investors. Other asset classes include commodities, currencies, interest rates, and indexes. The synthetic zero-coupon bond provides investors with elements of principal protections. Most of the structured notes are one hundred percent principal protected since investors receive their entire principals back along with any returns at maturity. Many structured notes are created in the form of a certificate of deposit and are insured by the FDIC. However, in the format of the note they commonly carry the issuers rating, which is commonly AA. These types of investments can also be constructed with leverage factors built in for additional capital appreciation potentials. With the principal protections the investor is protected to the downside, so the leverage has a distinct benefit of providing additional participation on the upside of the performance of the underlying options. For institutional investors these notes can be customized to gain exposures to almost any assets or indexes in long or short positions.

There are number of different management strategies that can be implemented when managing fixed income investments. First is active management strategy, where bonds are constantly being bought and sold, very similar to stocks for total return objectives. Overly active investment managements driven by pure emotions and market predictions, however, can be detrimental to the returns of fixed income portfolios. Second and more common management strategies are passive approaches. One of the passive approaches is the laddered portfolios. As bonds mature, additional bonds are bought with the principals received back, and typically extend the portfolios by another year. Next passive approach is the barbell strategy and it is where bonds are purchased that mature at the beginning and end of stated timeframes. The final passive strategy is the bullet strategy. In this strategy all bonds purchased in a 
portfolio mature in the same year. These strategies can all be very effective in appropriate interest rates environments when objectives of the investors are given.

\section{CASES FOR COMMODITIES AND CURRENCIES}

Commodities have become increasingly important assets that many investors should have some exposures to. Commodities can be divided into several different categories; energies, base metals, precious metals, basic materials, and agricultural commodities. The energies sector includes crude oil, natural gas, unleaded gasoline, and heating oil. The base metals sector includes steel, iron and copper and they are more important to many construction companies and home builders. The precious metals sector consists primarily of gold, silver, and platinum. Gold in the past was very significant back when many currencies were pegged to the value of the gold, known commonly as the gold standards. The basic materials sector contains many different commodities, but most commonly lumber and paper. The agricultural sector also contains a number of different commodities including wheat, corn, coffee, orange juice and sugar. Like energy, they are very important because they are used by everyone every day. And with ethanol getting so much attention as of late, the agricultural commodities seem to be the most interesting going forward.

One advantage to investing in commodities is the effect of correlation. Commodities are not correlated to most stocks and are not correlated to most bonds. This has an effect of reducing overall portfolios volatilities. Commodities are often considered to be one of the inflation indicators as well. As a result, investments in commodities often become an effective hedge against inflations. These factors make commodities as one of the important asset classes within portfolios.

Investments in different currencies are of significant to the performance of portfolios. Many investors in the U.S. are pretty much over-allocated to the dollar. It could be potentially detrimental if the value of the dollar declines. By investing in other currencies, investors are able to mitigate currency risks to certain extents, since many foreign currencies are negatively correlated to the U.S. dollar. In addition to hedging the risks of the dollar, investing in currencies also provides investors with advantage of diversifications. Investing in foreign currencies provide exposures to other economies that may be in phases of growth that are much larger than those of the United States. The foreign exchange (FX) market is also extremely efficient. It trades over 1.9 trillion dollars daily as the largest market in the world. While one would think that this makes it very easy to get exposure to this asset class, typically it takes trades of considerable sizes to get good exposures to the FX market. Trades of considerable sizes are common in other markets as well, such as the real estate markets.

\section{CASES FOR REAL ESTATE AND LIMITED PARTNERSHIP}

The investments in real estates are probably the largest investment for majority of the investors since the housings are one of the most sizable assets. Investing in other types of real estates, such as Real Estate Investment Trusts can be very beneficial as well since they are negatively correlated to stocks, bonds and commodities. In addition to this, many have abilities to provide monthly cash flows. The monthly cash flows are benefits that are also available from the investments in rental properties as well. These types of investments can play important roles in financial portfolios, but the investor must be careful not to be irresponsibly over-allocated to these asset classes.

Many investors, in contrast, do not have enough exposures to more limited asset classes such as Limited Partnerships. They are not very common in many investors, but they can be potentially prosperous. Limited Partnerships often provide exposures to private equities, giving them large capital gains potential. However, these investments are often not directly available to many investors. For institutional investors though, the exposures to venture capitals can be particularly advantageous similar to private equities. Venture capitals provide investors with potentials to hedge against emerging competitions or loss of market shares. They also provide abilities to pass through losses to the investors. There are some distinct tax advantages of limited partnerships as well, making them particularly attractive for many large investors with appropriate tolerance of risks. The tax advantages of investments are one of the important considerations that should be addressed when managing assets. 


\section{CASES FOR MUTUAL FUNDS}

There are also numbers of different management approaches to choose from when deciding how to invest. One of the emerging favorites among the investors, both in the retail and the institutional markets is the use of separately managed accounts. This is where investors select separate account managers to manage specific asset classes or multiple asset classes within portfolios. Many investors have opted to use multiple managers, essentially selecting specialists to manage asset classes. This may be less cost effective, but also ensures that all assets are managed by experts in their respective fields. The appeal of the separate account is the element of personalized attention. Managers provide this by creating customized portfolios and doing quarterly reviews and client meetings. This is something that is not commonly provided by brokerage firms.

Traditionally investors would invest directly in individual securities bought for them by brokers using brokerage accounts. There are several different brokerage accounts to choose from, one being an account at full service firms. Full service brokerage firms generally charge relatively high commissions, but provide high level of services, from investment advices to research and other support services. Discount brokerage firms are cost effective, but provide limited investment services and advices. Some of the problems with brokerage accounts are that they can be very time consuming for investors, and very often the case with the discount brokerage firms many assets are not available for investing. Good way of getting exposures to these investments is through the use of mutual funds.

Mutual funds are favorite choice among many investors. There are some very distinct advantages in using mutual funds. First, they are very easy to evaluate as performance and returns are readily available either from the mutual fund companies directly or through reporting agencies such as Morningstar. Mutual funds are also very easy to maintain for average investors because they can be bought and sold at any time without any extensive legal or paper works, as you would have with separately managed accounts. And like separately managed accounts, they provide investors with advantages of having professional managements. Also like separately managed accounts, they provide investors with opportunities to different assets within portfolios managed by specialists. The fees charged by the mutual fund companies can however be very detrimental to the returns to the investor. As an example, an indexed fund will always lag the performance of the benchmark as a result of the management and organizational fees, no matter how little they are.

The returns on mutual funds (or any investment for that matter) are also significantly affected by the inflation. Inflation can be very detrimental to the values of portfolios and overall financial health of investors. Inflation is the primary enemy to many bond portfolios because it reduces the future value of cash flows. In addition to this, the principal received at maturity will have less buying power when receive than it does today. The effect that inflation has on stocks is not quite as profound as it is on bonds, but it is still prevalent. For example, earnings must be appropriately evaluated and adjusted for the effect on inflation when doing a fundamental analysis. The value of dividends must be adjusted for inflation as the dividends that are earned will have less value at the time of payment than they do today at the time of evaluation. Inflation also has an impact on the prices of commodities as well.

\section{FINAL REMARKS}

The correlation between different assets is potentially one of the most important elements to consider when constructing portfolios. Non-correlated assets are particularly beneficial as they can help reduce overall portfolio volatilities and risks. Merrill Lynch has conducted studies in the development of the Optimal Multi-Asset Allocations. They show the importance of using multiple, non-correlated assets. This is demonstrated in the graph below. 
Chart 1: Risk Reduction by Number of Assets and Average Asset Correlation Assuming all assets have the same standard deviation and portfolio weight

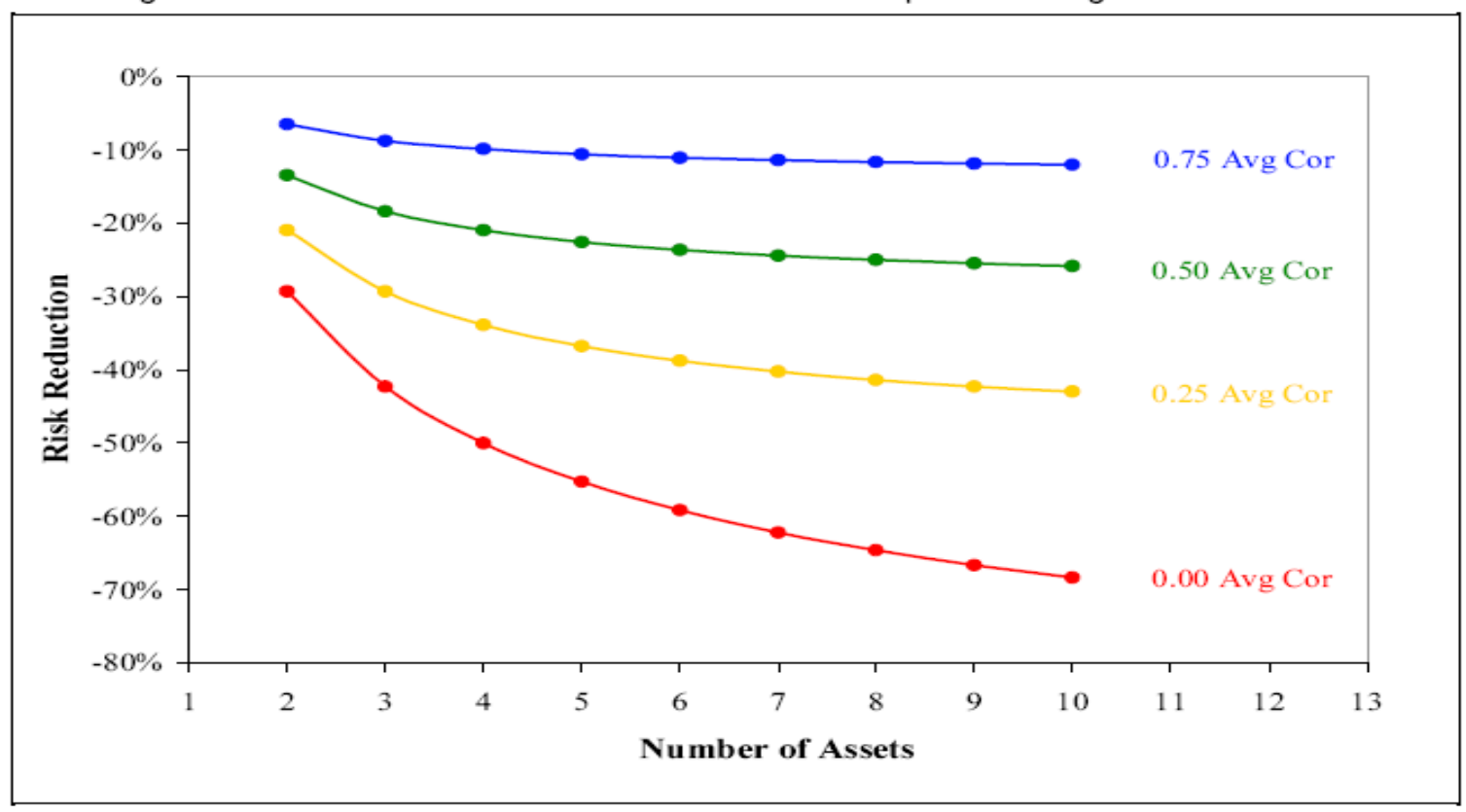

Source: Merrill Lynch Equity Derivatives Strategy

Investors could manage the risks and volatilities of the investments by constructing portfolios with multiple non-correlated assets since the values of the negatively correlated assets rise as the values of the certain assets go down.

Table 1: Historical Asset Correlations

Based on monthly Total Returns from 31 January 1991 through 30 December 2005

\begin{tabular}{|c|c|c|c|c|c|c|c|c|c|c|c|}
\hline & S\&P 500 & $\begin{array}{l}\text { Russell } \\
2000\end{array}$ & $\begin{array}{l}\text { MSCI ACWI } \\
\text { ex U.S. }\end{array}$ & $\begin{array}{c}\text { DJ-AIG } \\
\text { Commodities }\end{array}$ & $\begin{array}{c}\text { U.S. } \\
\text { Treasuries }\end{array}$ & $\begin{array}{c}\text { U.S. } \\
\text { Municipals² }\end{array}$ & $\begin{array}{l}\text { U.S. } \\
\text { Mortgages }^{3}\end{array}$ & $\begin{array}{l}\text { U.S. Inv. } \\
\text { Grade } \\
\text { Corporates }\end{array}$ & $\begin{array}{l}\text { U.S. High } \\
\text { Yield } \\
\text { Corporates }^{5}\end{array}$ & $\begin{array}{c}\text { U.S. } \\
\text { Convertible } \\
\text { Bonds }^{6}\end{array}$ & $\begin{array}{l}\text { U.S. } 12 \\
\text { Month } \\
\text { LIBOR }\end{array}$ \\
\hline S\&P 500 & 1.00 & 0.73 & 0.73 & 0.10 & -0.03 & 0.04 & 0.11 & 0.18 & 0.47 & 0.66 & 0.11 \\
\hline Russell 2000 & 0.73 & 1.00 & 0.66 & 0.19 & -0.14 & -0.02 & -0.02 & 0.08 & 0.52 & 0.79 & 0.04 \\
\hline MSCI ACWI ex U.S. & 0.73 & 0.66 & 1.00 & 0.25 & -0.08 & 0.00 & 0.04 & 0.10 & 0.44 & 0.60 & -0.09 \\
\hline $\begin{array}{l}\text { DJ-AIG } \\
\text { Commodities }\end{array}$ & 0.10 & 0.19 & 0.25 & 1.00 & 0.01 & 0.00 & -0.02 & 0.04 & 0.10 & 0.15 & -0.10 \\
\hline U.S. Treasuries ${ }^{1}$ & -0.03 & -0.14 & -0.08 & 0.01 & 1.00 & 0.80 & 0.87 & 0.92 & 0.11 & -0.03 & 0.19 \\
\hline U.S. Municipals² & 0.04 & -0.02 & 0.00 & 0.00 & 0.80 & 1.00 & 0.73 & 0.78 & 0.22 & 0.04 & 0.13 \\
\hline U.S. Mortgages ${ }^{3}$ & 0.11 & -0.02 & 0.04 & -0.02 & 0.87 & 0.73 & 1.00 & 0.86 & 0.23 & 0.09 & 0.27 \\
\hline $\begin{array}{l}\text { U.S. Inv. Grade } \\
\text { Corporates }\end{array}$ & 0.18 & 0.08 & 0.10 & 0.04 & 0.92 & 0.78 & 0.86 & 1.00 & 0.39 & 0.18 & 0.16 \\
\hline $\begin{array}{l}\text { U.S. High Yield } \\
\text { Corporates }\end{array}$ & 0.47 & 0.52 & 0.44 & 0.10 & 0.11 & 0.22 & 0.23 & 0.39 & 1.00 & 0.50 & 0.08 \\
\hline $\begin{array}{l}\text { U.S. Convertible } \\
\text { Bonds }^{6}\end{array}$ & 0.66 & 0.79 & 0.60 & 0.15 & -0.03 & 0.04 & 0.09 & 0.18 & 0.50 & 1.00 & 0.08 \\
\hline $\begin{array}{l}\text { U.S. } 12 \text { Month } \\
\text { LIBOR }^{7}\end{array}$ & 0.11 & 0.04 & -0.09 & -0.10 & 0.19 & 0.13 & 0.27 & 0.16 & 0.08 & 0.08 & 1.00 \\
\hline
\end{tabular}

Source: Merrill Lynch Equity Derivatives Strategy 
The goal of using non-correlated assets is to shift the efficient frontier up and to the left as much as possible. The portfolio with optimal allocation is found where the capital market line is tangent to the efficient frontier. In order to maintain financial stability, investors should maintain proper diversifications and asset allocations within their portfolios of financial assets. The use of all different types of assets, specifically those that are non-correlated is an approach that is necessary to the management of successful financial portfolios. Obtaining the optimal multi-asset allocation is essential in the pursuit of obtaining the greatest amount of return for the desired level of risk, which is the ultimate goal of the investment.

\section{REFERENCES}

1. Jahnke, William W., The Asset Allocation Hoax, February 1997

2. Rosenberg, David A.; Bernstein, Richard, Merrill Lynch Pierce Fenner \& Smith, U.S. Economic and Financial Markets: As US housing goes, so goes the global economy, December 6, 2005

3. Friedlander, George and Brandes, Michael, Citigroup, Private Client Investment Strategy Group: Fixed Income Strategy -The Risk of Risk Aversion, June 8, 2005

4. Rosenberg, David, Merrill Lynch Pierce Fenner \& Smith, Economic Commentary: Housing Bubble - Is This A Stable Backdrop?, July 18, 2005

5. Khan, Kim \& Blaine, Charley, CNBC, CNBC Market Dispatches, September 15, 2005

6. Ebens, Heiko; Kariwala, Siddharth; Davi, John \& Bowler, Benjamin; Amanti, Giovanni, Merrill Lynch Pierce Fenner and Smith, Equity Derivatives Strategy - Optimal Multi-Asset Allocation: Monetizing the Risk Reduction That Is Achieved Via Diversification, February 3, 2006 


\section{NOTES}

